\title{
Quantifying Family Spillover Effects in Economic Evaluations: Measurement and Valuation of Informal Care Time
}

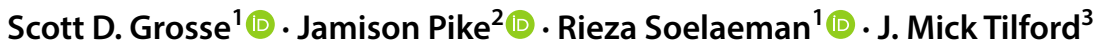

Published online: 6 April 2019

(c) The Author(s) 2019

\begin{abstract}
Spillover effects on the welfare of family members may refer to caregiver health effects, informal care time costs, or both. This review focuses on methods that have been used to measure and value informal care time and makes suggestions for their appropriate use in cost-of-illness and cost-effectiveness analyses. It highlights the importance of methods to value informal care time that are independent of caregiver health effects in order to minimize double counting of spillover effects. Although the concept of including caregiver time costs in economic evaluations is not new, relatively few societal perspective cost-effectiveness analyses have included informal care, with the exception of dementia. This is due in part to challenges in measuring and valuing time costs. Analysts can collect information on time spent in informal care or can assess its impact in displacing other time use, notably time in paid employment. A key challenge is to ensure appropriate comparison groups that do not require informal care to be able to correctly estimate attributable informal care time or foregone market work. To value informal care time, analysts can use estimates of hourly earnings in either opportunity cost or replacement cost approaches. Researchers have used widely varying estimates of hourly earnings. Alternatively, stated-preference methods (i.e. contingent valuation, conjoint analysis) can be used to value the effect of informal care on utility, but this can entail double counting with health effects. Lack of consensus and standardization of methods makes it difficult to compare estimates of informal care costs.
\end{abstract}

\section{Introduction}

The term "spillover effects" in cost-effectiveness analysis (CEA) was introduced by Basu and Meltzer [1] in 2005 to describe the effects of conditions and treatments on different aspects of the welfare of family members. Failure to include spillover effects in CEA can lead to underestimation

Electronic supplementary material The online version of this article (https://doi.org/10.1007/s40273-019-00782-9) contains supplementary material, which is available to authorized users.

Scott D. Grosse

sgrosse@cdc.gov

1 National Center on Birth Defects and Developmental Disabilities, Centers for Disease Control and Prevention, 4770 Buford Highway NE, MS E-87, Atlanta, GA 30341, USA

2 Immunization Services Division, National Center for Immunization and Respiratory Disease, Centers for Disease Control and Prevention, Atlanta, GA, USA

3 Department of Health Policy and Management, Fay W. Boozman College of Public Health, University of Arkansas for Medical Sciences, Little Rock, AR, USA of treatment benefits. Numerous studies have now assessed spillover effects on the health (and health-related quality of life) of family members of individuals affected by a chronic condition [2-4]. Such health effects on family members are non-monetary and are appropriately included in the denominator of a cost-effectiveness ratio in economic evaluations from the societal perspective. All else equal, including spillover benefits in the denominator reduces the estimated cost-effectiveness ratio.

It is also recognized that conditions and treatments can generate another form of spillover effects through the need for unpaid informal care. The impact of informal caredefined as unpaid care provided by family members to individuals with a medical condition or disability—on time use as distinct from 'effects' on health is appropriately included as a monetary time cost in the numerator of a cost-effectiveness ratio [5]. All else equal, including spillover costs in the numerator increases the cost-effectiveness ratio. Interventions that reduce the prevalence of chronic conditions or improve functioning should reduce spillover costs and increase spillover benefits, resulting in incremental costeffectiveness ratios that are lower due to the inclusion of both types of spillover effects. 


\section{Key Points for Decision Makers}

Costs of informal care time are an important spillover effect that should be included in economic evaluations of health interventions if likely to be significant.

Differences in methods and data sources make it difficult to compare estimates of informal care costs.

Researchers who plan to include both caregiver health effects and time costs should choose methods that minimize double counting of spillover effects.

Recommendations on the inclusion of spillover effects has changed over time. In 1996, the first US Panel on CostEffectiveness in Health and Medicine (First Panel) called for the inclusion of informal care time costs in societal perspective analyses [6]. The First Panel also recognized the potential value of including health effects on family members but did not recommend their inclusion in a reference case societal-perspective analysis. In practice, informal care was not included in societal-perspective analyses, except in a few specific areas, notably dementia management [7-9]. The second US Panel on Cost-Effectiveness in Health and Medicine (Second Panel) in 2016 called for the inclusion of both health effects on family members and informal care time costs in societal-perspective analyses [10]. In particular, it was recommended that informal care time be included in an inventory of costs and considered for inclusion depending on the study perspective, availability of data, and the likelihood that its inclusion would have a substantial effect on cost estimates. That recommendation is consistent with previous calls by Brouwer and colleagues [11, 12]. However, the growing recognition of the importance of informal care has not been accompanied by a consensus on methods for inclusion in economic assessments [12]. Several methods can be used for measuring and valuing informal care time, which can lead to variability in estimates.

While both health effects and informal care time costs represent spillover effects on family welfare [13], analysts typically have considered either the non-monetary valuation of effects or the monetary valuation of time for inclusion. Indeed, a recent review of informal care pointed to a choice of methods for valuing either monetary costs or non-monetary effects based on the research question, data availability, and other considerations [14]. Although CEAs typically do not include both types of effects $[8,15]$, we suggest it would be logical to include both types of spillover effects. The challenge is to avoid double counting, which-in the context of spillover effects-often refers to the distinction between a caregiver's disutility of seeing a relative ill and the disutility of their own health effects $[16,17]$. Our concern is potential double counting of the disutility of informal care burden on the caregiver's own utility and the monetary value of their time. We suggest that analysts who wish to follow the societal perspective use 'pure' methods to value informal care time costs so that both types of spillover effects can be appropriately included in a single analysis [18].

In this review, we consider methods for the inclusion of informal care time costs with an explicit consideration of methodological issues that can arise by incorporating both monetary and non-monetary effects in a CEA. We first discuss the methods that can be used to measure informal caregiving time, such as the diary and recall methods. Next, we provide an overview of different approaches to valuing caregiving time, including revealed-preference methods (i.e. replacement and opportunity cost) and stated-preference methods (i.e. contingent analysis and conjoint valuation). In addition to describing each method and providing examples for each method, we also discuss key considerations and potential sources of bias when using the method to help researchers decide the most appropriate approach to answer their question.

\section{Measurement of Care Time}

A first empirical challenge in the valuation of informal care time in cost-of-illness (COI) analyses and CEAs is the decision whether to attempt to directly measure time spent in informal care or instead to assess its impact in displacing other time uses, notably paid employment. That choice is not independent of the choice of valuation methods, since the replacement cost method requires direct estimation of time, whereas the opportunity cost method requires estimation of displaced time uses (see Sect. 3.1.2). Assessing displaced time use also involves conceptual challenges. Focusing on time displaced for employment implicitly places a lower or even null value on other displaced time use, such as leisure. Whether that approach is appropriate may depend on the analytic perspective. For example, many COI studies restrict estimates of indirect or productivity costs of disease to foregone market earnings; it is logically consistent for such COI studies to also value informal care in terms of foregone earnings. In any case, researchers who focus on displaced paid work would be well advised to clarify that such a focus still implies that other uses of time are valued.

Another challenge is the endogeneity of substitution of informal care for other time uses, notably paid work. It is often assumed that informal care substitutes for formal home care, but that can vary. One study found that the opportunities for substitution in care provided by adult children for elderly parents are limited to unskilled care and with limited number of hours of care required [19]. In addition, it is often 
assumed that informal care substitutes for paid work, but that also varies. Provision of informal care may lead to relatively modest reductions in paid work for women and little or no substitution for men [20, 21].

\subsection{Diary and Recall Methods}

Hours of informal care can be directly measured using either the recall method or the diary method. For the recall method, respondents record how much time they spend on a list of activities during a previous time period (day or week). The diary method is often referred to as the gold standard in measurement of informal care time because activities are prospectively recorded as they are conducted during a specified time period. However, implementation of this method may not be feasible because it requires substantial time and effort from both respondents and researchers [15, 22]. Therefore, most studies that state the method used to directly estimate informal care time use a recall method [23].

\subsubsection{Key Considerations and Potential Sources of Bias}

Both the time diary and recall methods use survey instruments to elicit informal care time, and both have limitations. Prospective time diaries may not do a good job of capturing episodic activities of short duration, unless very short intervals are used for recording time [24]. Retrospective recall methods are subject to bias, depending on how questions are posed to respondents [25]. For example, asking a caregiver how much time they spent on certain activities versus asking what activities were conducted within a given time period can lead to widely different estimates [25, 26]. According to one study, although diary estimates were more precise than recalls in the aggregate, both methods produced similar results [22]. However, it has been reported that caregivers when asked to recall informal care time underestimated time spent in "support" of care recipients, especially "stand-by" time, i.e. time spent actively waiting to provide care, compared with time recorded in a daily diary, especially caregivers aged $>65$ years [27].

An important consideration in the measurement of informal care time is joint production [25]. Joint production occurs when a caregiver performs more than one care activity or is performing another non-care activity, such as leisure or regular household activities, while performing informal care [23]. Respondents can be asked to report all activities conducted within a specific timeframe (i.e. $30 \mathrm{~min}$ ), but the researcher must then decide how to allocate that time across those activities. Van den Berg and Spauwen [22] found that respondents using the recall method reported significantly more time allocated to informal care than those using a diary, but - when researchers adjusted diary estimates for joint production-there was no significant difference between the two methods.

Perhaps the biggest challenge in assessing informal care time is to distinguish tasks that are performed because an individual requires care due to disease or disability versus tasks that are regular activities of daily living (ADL). Since elderly people and young children generally require considerable care, even in the absence of disease or disability, it is often difficult to determine how much of the time spent engaging in informal care is attributable to the condition as opposed to usual care [14]. Some studies simply estimate total hours of respondent-reported informal care [28]. However, such estimates can overstate the burden of informal care if researchers do not estimate the hours of care attributable specifically to a health condition $[25,29]$.

To calculate attributable hours of care, researchers can use a demographically matched comparison group that does not require care due to a health condition and use statistical methods to control for confounding by demographic and socioeconomic factors, e.g. age, sex, and insurance type. To illustrate, the total hours of informal care for stroke survivors has been reported to range from 12.4 to $22 \mathrm{~h}$ per week [ 30 , 31], but incremental hours of informal care due to stroke ranged from 2.5 to $12.5 \mathrm{~h}$ per week [32, 33], roughly half as much [34]. In another study, an injurious fall among older stroke survivors was associated with an unadjusted additional burden of $14.0 \mathrm{~h}$ per week of informal care and an adjusted estimate of $10.1 \mathrm{~h}$ controlling for confounding [35].

Another important choice involves the definition of informal care. Research studies may opt for global estimates using a broad definition of informal care or may focus on specific sets of activities. In particular, some studies may only include time spent on ADL, such as bathing, dressing, and eating, or instrumental ADL (IADL) activities, such as shopping, cooking, transportation, and managing money. Other studies may include any time spent in the company of a care recipient, including social/recreational activities or standing by to provide care when needed. For example, Ostbye and Crosse [36] reported caregivers spending between 67 and $98 \mathrm{~h}$ per month on ADL/IADL care for adults with dementia, whereas a comparison group of caregivers of elderly people without cognitive impairment reported spending $19 \mathrm{~h}$ per month on ADL/IADL care. In that study, the attributable hours of care due to dementia were the between-group difference of 48 to $79 \mathrm{~h}$ per month. Rice et al. [37] reported that adults with Alzheimer's dementia received an average of $286 \mathrm{~h}$ of care per month, just over half of which was for ADL/IADL care; the remaining hours were for social/recreational activities or behavioural management.

The Erasmus group in the Netherlands developed an instrument to measure informal care time using the recall 
method, the Institute for Medical Technology Assessment Valuation of Informal Care Questionnaire (iVICQ) [29]. The iVICQ requests estimates of hours spent in the past week providing care in three types of activities: personal care, household activities, and practical support. For the same three categories, respondents are also asked how many fewer weekly hours of care would have been performed if the care recipient were in good health or could have independently done them. The personal care activities correspond to ADLs, whereas the household activities (food preparation, cleaning, washing, ironing, sewing, taking care of and playing with your children, shopping or maintenance work, odd jobs, gardening) are IADLs. The practical support category includes IADLs (e.g. transportation and financial management) and social/recreational activities (e.g. visiting family and friends), as well as care coordination.

The iVICQ also seeks to elicit estimates of caregiver time displaced by informal care. First, it asks how many fewer hours the caregiver spends per week on paid work, unpaid work, and leisure time since they began providing care. Second, it asks how many additional hours of paid work, unpaid work, and leisure the caregiver would perform if they no longer had to provide informal care [29].

\section{Valuation}

Valuation of informal care time in COI analyses and CEA can be pragmatic, using data on hourly earnings as estimates of time costs, or through stated-preference studies, which seek to elicit individual respondents' willingness to pay (or accept) for variations in the amount of time individuals would hypothetically allocate to caregiving [38, 39]. It has been argued that the use of earnings can be considered a revealed-preference approach in which the value of informal care time is inferred from informal caregivers' decisions or from decisions in the market for close substitutes of informal care [25]. Although both approaches are well-established and can yield credible estimates, the two types of methods can be expected to produce varying valuation estimates. These approaches are discussed in the next few sections, and Table 1 summarizes the advantages and disadvantages of each approach. In addition, there is considerable heterogeneity of estimates within each approach.

\subsection{Use of Earnings Estimates}

Analysts commonly take one of two broad approaches to the valuation of informal care time using earnings data: the opportunity cost approach and the replacement cost (proxy good) approach $[8,15,25,40,41]$. An international review of 68 studies of informal care costs for neurological disorders found that 18 studies used a replacement cost approach and 50 used an opportunity cost approach [42]. Some studies have used the opportunity cost approach to value displaced paid work and the replacement cost approach to value displaced unpaid work [43, 44]. That is consistent with the approach that has long been used in the USA to estimate productivity losses in which gross earnings are used to value loss of paid work and the replacement cost method is used to value unpaid work [45, 46]. Different valuation approaches may yield different estimates, particularly when using earnings estimates that differ in the inclusion of taxes, fringe benefits, overheads, etc. or using mean, median, or minimum wages. The conceptually correct measure of earnings may differ if the target population is likely to earn significantly more or less than the population average.

\subsubsection{Replacement Cost Approach}

In the replacement cost (proxy good) approach, analysts value time for types of informal care based on the projected cost of paid caregiving services that would need to be hired if informal care were not available. In particular, European health economists have recommended measuring all informal care time and valuing it using the replacement cost approach. Researchers at Erasmus University in the Netherlands have developed detailed guidance [15, 30, 47]. The method entails an itemized list of hours spent by caregivers providing two types of services, assuming a housekeeper is hired for ADL services and a nurse for IADL personal care services [30]. Version 1.1 of the iVICQ instrument developed by the Erasmus group uses a shadow price for household services of $€ 8.50 / \mathrm{h}$ and for personal care of $€ 35 / \mathrm{h} \mathrm{[15].}$

One advantage of the replacement cost method is that the market value of a task can be estimated once and used in different caregiving situations. Another advantage is that, because it considers only the caregiver's inputs, double counting with health effects is not expected. A third advantage of the replacement cost approach is that, for economic evaluations of interventions affecting individuals who require home care, some of whom have family caregivers, the cost of providing such care would be counted regardless of whether it is paid or unpaid care. In the absence of accounting for the replacement cost of informal care time, rehabilitation costs would be undervalued for those with spouses or other family members willing and available to provide uncompensated care because their opportunity cost of time would likely be much lower than the replacement cost. It should be noted that analysts who use the replacement cost approach sometimes refer to it as the opportunity cost approach [32, 48], which can cause confusion.

\subsubsection{Key Considerations and Potential Sources} of Bias The estimation of what it would cost to hire household and personal care services can be challenging for 


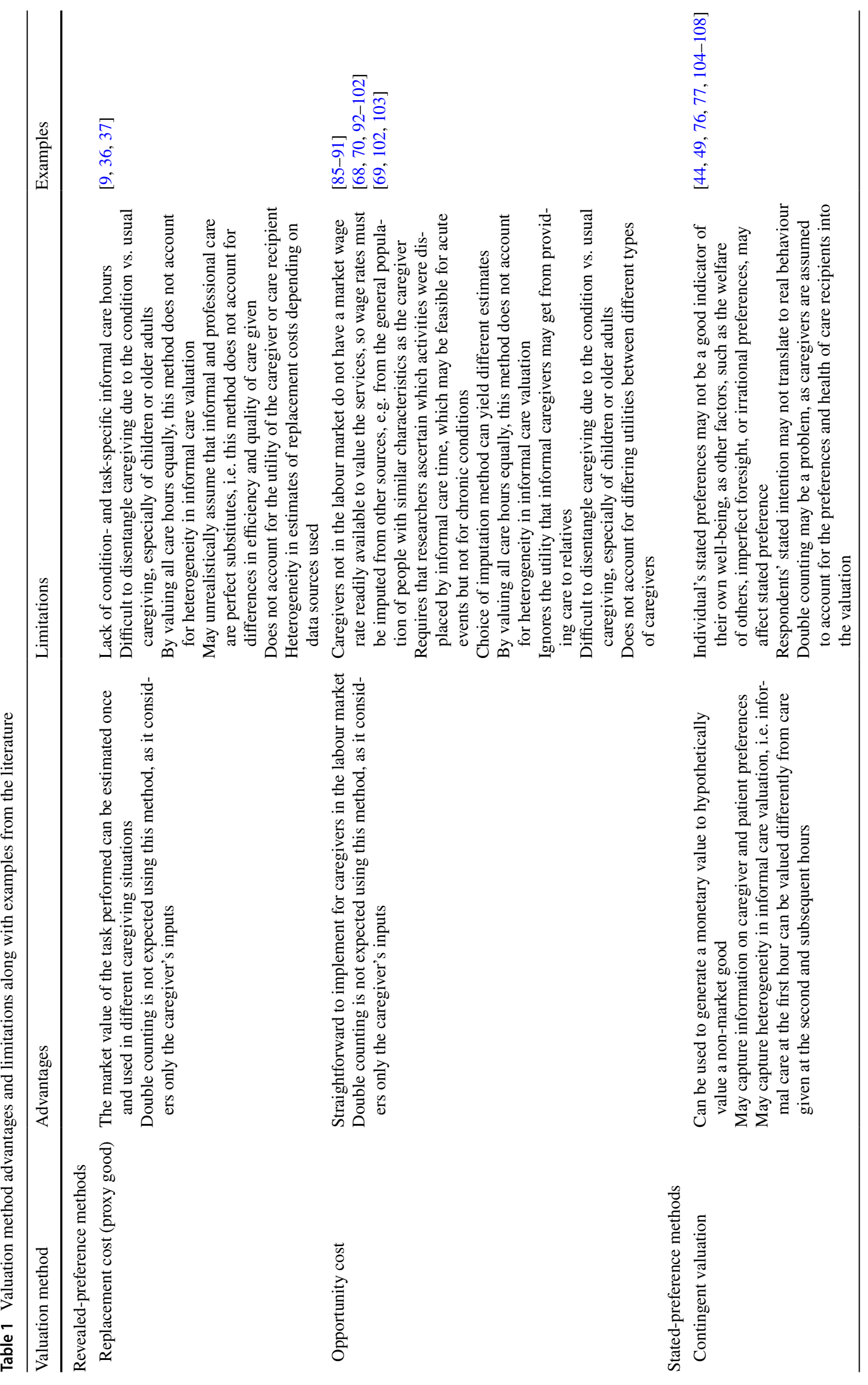




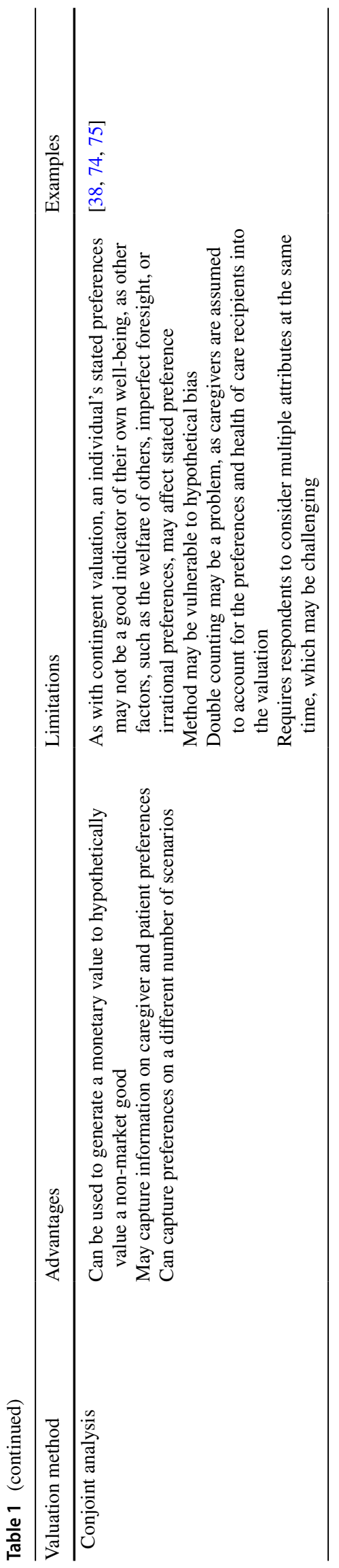

both conceptual and empirical reasons. Conceptually, this approach implicitly assumes that informal care and paid care are perfect substitutes, which is unlikely to be the case [49]. Indeed, informal care only partially substitutes for paid care and in some situations may be a complement [19].

Both the measurement and the valuation of informal care time stratified by tasks of varying skill levels can be empirically challenging. Some North American studies using the replacement cost approach have calculated hourly costs for several distinct occupations: nursing assistant, housekeeper, bookkeeper, and handyman, inclusive of employee benefits $[36,37,48]$. For convenience, some analysts use wages for a single occupation, e.g. home health aides [28, 35]. However, that may overstate the replacement cost for housekeeping services. Arno et al. [50] calculated the average of the wage of home healthcare aides and the legal minimum wage, and others have calculated parallel estimates using average wages of home health aides and the legal minimum wage $[28,35]$.

Depending on the source of data used, the replacement cost approach can yield varying estimates of informal care costs [14]. For example, Guerriere et al. [43] estimated the value of displaced unpaid work using the average Canadian gross wage of \$Can 18.32 for "homemakers" (i.e. housekeepers), adjusted for benefits, and in a sensitivity analysis used a combination of a gross wage of \$Can29.71 for personal support workers and an hourly cost of \$Can 26.00 for a maid service (year 2005 values) [43]. Two recent US studies used very different estimates of the hourly cost of home health aides, \$US24.14 [28] and \$US10.54 [35] (year 2015 values).

Differences in the estimates of the replacement cost of informal care as documented above can result from some studies using hourly wages for occupations and others using hourly fees charged by agencies that provide home housekeeping or healthcare services. Using hourly fees charged by agencies may be more appropriate, since the use of hourly wages undervalues informal care for multiple reasons. First, such estimates ignore the fixed costs of hiring care, which is generally hired in blocks of time with a minimum of a half-day. If live-in care is required, the hourly cost may be substantially greater. A further challenge is that, for completeness, the replacement approach should not only address hiring people to perform specific services but also the cost of recruiting and monitoring hired caregivers. The hourly cost of care charged by home healthcare agencies, which includes the costs of supervision and administration, can be twice the wage paid to a home health aide [51]; a Canadian study assumed a ratio of 1.8 times hourly wages as a "realistic" approach to estimating the replacement cost of informal care provision [52].

An additional limitation of the replacement cost approach as usually implemented is the exclusion of the cost of care management services provided by family members or 
close friends in economic studies of informal care costs. Care management, which includes accompanying the care recipient to appointments with healthcare providers, communicating and coordinating care with providers (including home health aides, and counselling the care recipient about treatment adherence, diet, and other behaviours), is done by a large percentage of caregivers [53, 54]. For example, one study of Canadian informal caregivers of older adults found that $84 \%$ of caregivers performed managerial care [53]. Charges for such services in the USA can amount to \$US50-100/h (Goodman A, personal communication; 14 June 2018).

By valuing informal care time as equal in value to professional care, the replacement cost approach distinguishes the monetary value of care from the utility of care and estimates only the former. Although some have criticized that approach for not capturing utility or disutility of the informal caregiver and recipient [25,49], in our view, this is an advantage, not a limitation, since it avoids double counting of non-monetary and monetary valuations of informal care.

\subsubsection{Opportunity Cost Approach}

3.1.2.1 Imputation of Hourly Earnings to Value Estimated Hours of Informal Care In the opportunity cost approach, analysts assign monetary values to informal care based on the assumed opportunity cost of the caregiver for displaced time use. Similar to the replacement cost approach, double counting is not expected, because only caregivers' inputs are considered. The opportunity cost approach to valuing informal care time is challenging to implement $[12,25,47]$. It requires that researchers ascertain which activities were displaced by informal care time. For acute events, it is possible to compare before-and-after time use patterns. For chronic conditions, that is not feasible, but respondents can be asked what they would do with their time if not providing care. ${ }^{1}$

For reduced hours of work among caregivers who remain employed, it is straightforward to use the caregiver's wage. For those not in the labour force, a wage can be imputed based on the earnings of demographically matched individuals [55, 56]. Imputation of hourly earnings to value informal care hours poses both conceptual and empirical challenges. Some researchers prefer to impute wages for all caregivers $[43,57]$, and other analysts conservatively use the minimum wage to value informal care time [58]. Of a sample of 50 studies that used the opportunity cost approach to evaluate the economic burden of informal nurse care, five reportedly used caregiver's lost earnings, and other studies multiplied

\footnotetext{
${ }^{1}$ If caregivers report greater utility from providing care than from displaced leisure care, time may not have a positive opportunity cost (Perou R, personal communication; 12 December 2017).
}

care hours by an hourly wage, whether the average gross or net wage in the economy, the minimum wage, or the caregiver's own wage [42]. The choice of imputation method can yield very different estimates of the opportunity cost of informal care [40].

Conceptual challenges result from heterogeneity in earning potential. Imputation of wages based on observed characteristics such as age, sex, and years of education can understate the opportunity cost of time for individuals who have relatively high earning potential associated with unobserved characteristics. Similarly, use of mean, median, or minimum hourly wages for the population may overstate the opportunity cost of time of low earners and understate the opportunity cost for high earners.

Another source of heterogeneity in estimates is the decision whether to use gross wages, inclusive of benefits, or net wages, i.e. the wage after employer deductions. The social opportunity cost of paid work is the employer cost of compensation, since it is employer cost that is equated to the marginal product of labour [59]. Many economists argue that the market wage is the relevant shadow price for all types of time use, including leisure [12, 41], although the post-tax hourly wage is relevant for labour-leisure tradeoffs. Some economists assume a lower value of displaced leisure or personal care time, often taking a fraction of the hourly wage [59]. On the other hand, it can be argued that the market wage may be a lower bound for the value placed on non-market activities [41].

\subsubsection{Use of Displaced Paid Work or Household Income as Proxies for the Opportunity Cost of Informal Care Infor-} mal caregivers often see a reduction in earned income through either dropping out of the labour force or remaining employed while reducing hours of paid work [24]. For that reason, researchers often use displaced paid work as a proxy measure of the opportunity cost of informal care. Typically, researchers using that approach multiply lost hours of paid work attributed to informal care by the individual's hourly earnings or by an imputed wage. That approach was endorsed by the First Panel for the calculation of patient time costs [55] and was included in a worked example of informal care time costs [60].

Valuing displaced work time in this way is consistent with the human capital approach that is commonly used to assess productivity losses (indirect costs) associated with disease, disability, or premature death [61-63]. The Second Panel endorsed using this method for valuing productivity losses incurred by either patients or caregivers [10]. The alternative friction cost approach to estimating lost earnings yields much lower estimates of the opportunity cost of informal care [64].

Not all caregiving activities displace paid employment; some groups of informal caregivers experience displacement 
of paid work to a greater degree than others. In particular, the friction cost approach can seriously undervalue the opportunity cost of informal care provided by caregivers who are retired or otherwise not actively engaged in the labour force prior to initiating informal care. In addition, secondary caregivers, especially caregivers who do not reside with care recipients, appear unlikely to experience reduction in paid employment [65], and their caregiving is not valued in this approach. Conversely, among primary caregivers, greater intensity of informal care is associated with reduced labour force participation, even controlling for the endogeneity of informal care and labour force participation [66, 67].

Multiplying reduced hours of employment by the hourly wage can understate the opportunity cost of informal care if primary caregivers experience lower hourly earnings resulting from interruptions in employment. For example, in a US study, Tilford et al. conservatively assumed that hourly wages were unaffected by care responsibilities [68]. In that study, primary caregivers earned about $25 \%$ less per hour than in a matched population sample, and the loss of annual earnings may have been greater than estimated. It should also be acknowledged that the existence of a wage penalty may be dynamic, increasing over time following disrupted labour market attachment due to inability to earn promotions or change employment for higher-paying positions. A recent study found no immediate effect of reduced full-time work on hourly earnings but considerable long-term reduction in hourly earnings [21].

In place of estimating reduced hours of work and multiplying by hourly earnings, some researchers directly estimate differences in annual earnings for samples of affected and unaffected families $[69,70]$. That approach has the potential advantage of incorporating effects of reduced work attachment owing to caregiving responsibilities on hourly earnings as well as hours of work. It can also capture differences for multiple household members. In one study that estimated both reduction in annual household income and reduced hours of paid work, the former was substantially larger in magnitude than would be implied by the loss of hours of paid work [70].

To sum up, studies that restrict estimates of the opportunity cost of informal care to reductions in market work and earnings seriously underestimate the overall economic burden of informal care since they assign no monetary value to other time uses that may be displaced by informal care. Moreover, such studies may differentially underestimate the burden of informal care, not valuing care provided by those who are either outside the labour market or who provide secondary care that does not affect their paid employment. It is suggested that studies that follow this approach also conduct a sensitivity analysis in which all care hours are valued equally, if it is possible to estimate attributable hours of informal care. However, a strength of valuing lost hours of paid work is that it can be done by comparing objectively reported hours of paid work for samples of caregivers from affected and unaffected families rather than asking caregivers to speculate how care displaced other activities. Furthermore, for young children and the elderly, it can be difficult to distinguish informal care hours due to a health condition from usual caregiving requirements in the absence of a health problem.

\subsection{Stated-Preference Methods}

Two types of stated-preference methods are commonly used in health economics to estimate shadow prices where market prices either do not exist (non-market goods) or may not be generalizable: contingent valuation (CV) and conjoint analysis (CA) methods [15, 39]. Unlike the opportunity cost and replacement cost methods, stated-preference methods can capture the preferences of both the informal caregiver and the patient. The utility that informal caregivers derive from providing informal care is appropriate to include in a full cost-benefit analysis. For analyses that separately estimate spillover effects on caregiver health and the valuation of informal care time, certain stated-preference methods can be used that minimize the risk of double counting the utility of health and of time use [18].

With CV, one can assess the minimum amount an informal caregiver is willing to accept to provide an additional hour of informal care or willing to pay to not give an additional hour [49]. For example, the iVICQ tool developed by the Erasmus group asks two CV questions. First, the respondent is asked how much they would be willing to accept from the government to provide 1 extra hour of informal care per week with categories of $€ 0, € 1-5, € 6-10$, etc., up to $>€ 50$. It then asks the respondent how much they would be willing to pay someone to take over part $(1 \mathrm{~h}$ per week) of their responsibility of providing informal care, using the same categories. CV questions can also be asked of care recipients to value informal care from their perspective.

Conjoint refers to the joint consideration of preferences over multiple attributes. The primary application of CA is the discrete-choice experiment (DCE), in which respondents are presented with a limited number of attributes of a hypothetical product and asked to choose the combination of attributes that best reflects their preferences. The CA and DCE terms are often used interchangeably in health economics $[71,72]$. The approach, which was developed in marketing research and environmental economics, has been widely adopted in health economics [73]. For example, the respondent may be asked to choose between two or more informal care situations, described by different characteristics or attributes. Attributes may include the number of hours of care per week and the type of care activity, as well as a monetary attribute. Having respondents make several 
choices and varying the levels of the attributes allows the researcher to derive implied preferences for attributes.

A few researchers have used CA or DCE to calculate the monetary value of informal care $[15,18,38,74,75]$. WTP or willingness to accept (WTA) can be indirectly estimated by dividing the estimated utility difference for different values of one attribute by an assumed constant marginal utility of a dollar [72].

\subsubsection{Key Considerations and Sources of Potential Bias}

One criticism of stated-preference studies, both CV and CA, is that they are vulnerable to hypothetical bias. That is, these methods may not capture 'true' preferences, since there are no real market consequences for the respondent, although some studies suggest they are sensitive to individual circumstances of caregiving (e.g. requiring higher payments for more labour-intensive tasks) $[49,74,76,77]$. Also, substantial numbers of respondents may choose not to participate in the exercises because of their hypothetical nature [76].

It is important to conduct external validation using evidence of revealed preferences because respondents may overstate their willingness to pay (WTP) when faced with hypothetical scenarios compared with actual choices when they are obliged to pay money [78]. In one meta-analysis of CV estimates, List and Shogren [79] found that CV respondents overstated preferences as much as threefold. A recent meta-analysis of CV studies found more variability, with many studies showing a smaller magnitude of bias [80]. Another issue is that informal caregivers who are satisfied with their role are less likely to participate in CV surveys than those who are dissatisfied, thereby subjecting WTP/ WTA estimates to upward bias [76].

Although some researchers have reported external validity of DCE estimates to predict behaviour [81], this does not necessarily apply to monetary estimates of WTP [78]. If a constant marginal utility of income does not hold, linear WTP estimates may be unreliable [82]. In addition, incorporating utilities into valuation of informal care time makes stated-preference methods vulnerable to double counting with health outcomes if caregivers take into account the preferences and health of care recipients. Finally, an individual's stated preferences are not necessarily a good indicator of an individual's well-being because they may be considering the welfare of others, may have imperfect foresight, or may exhibit irrational preferences [25]. Therefore, we suggest that analysts either use stated-preference methods (CV or CA) to value the utility or disutility of informal care, including its health effects, or separately analyse the effects on health and value of time. Hoefman et al. [18], in their DCE analysis of WTA for informal care time, calculated a 'pure' measure of time by including attributes to adjust for other effects of informal care.

\section{Discussion}

The recognition that health interventions, diseases, and conditions produce spillover effects on family members has led to growing attention to the incorporation of these effects in terms of health or lost productivity in CEA and COI analyses. Indeed, the Second US Panel now explicitly recommends the incorporation of both informal caregiver health and productivity effects in reference case societalperspective CEAs of health interventions. Informal care time should be included in an inventory of costs and considered for inclusion depending on the study perspective, availability of data, and the likelihood that its inclusion would have a substantial effect on cost estimates.

This review suggests that the literature, with rare exceptions [18], has not sufficiently considered accounting for both health and productivity effects in the same analysis. In particular, the inclusion of health and productivity effects in a CEA gives rise to the potential for double counting. There are also issues of endogeneity in the allocation of time between market and non-market work and between productive time and time in health-promoting activities.

Because informal care can affect both productivity and health, care needs to be taken to understand the consequences of approaches to measuring and valuing informal care. Informal care can displace leisure and personal care time as well as market and non-market productive time. It might be argued that economic estimates of foregone earnings are conservative estimates of the economic burden of informal care responsibilities since they ignore other displaced time uses. On the other hand, economic estimates of overall informal care time can involve double counting with health effects, which are typically represented in quality-adjusted life-years (QALYs). If properly specified [18], WTP/WTA estimates of informal care may be suitable for inclusion in CEAs that assess spillover effects on health of family members using QALYs.

A concrete example of endogeneity between informal care time and health is the association of informal care with sleep time. Caregivers of more severely affected children with spina bifida up to 6 years of age in Arkansas, USA, reported an average loss of $1.1 \mathrm{~h}$ per night of sleep relative to caregivers of children with less severe lesions (5.6 vs. $6.7 \mathrm{~h}$ ) [83]. Reduced sleep is associated with worse self-reported quality of life as demonstrated by a survey of caregivers of children with autism spectrum disorder. Researchers found that $25 \%$ of caregivers reported averaging $\leq 5 \mathrm{~h}$ of sleep per night compared with $3 \%$ of the general population; those caregivers also had significantly worse health state utility scores than caregivers who averaged $\geq 7 \mathrm{~h}$ of sleep per night [84]. 
The diary and recall methods for measurement of informal care time each have advantages and limitations [23, $25]$. The chief advantage of recall methods is that they can be incorporated in large surveys. Recent recalls, i.e. activities within the past week, are more accurate. A much more important methodological issue is the collection of the same time use data from comparison groups of families unaffected by disease or disability. Use of unadjusted estimates of informal care time can result in substantial overestimates of the economic burden of informal care.

The replacement cost and opportunity cost approaches for valuation of informal care time also have advantages and limitations. Each approach should be applied to data on care time that are differentiated either by displaced activities (opportunity cost) or type of informal care (replacement cost). The opportunity cost of informal care depends on which activities are displaced, and likewise the replacement cost of informal care services can vary greatly depending on the task. The replacement cost approach may not fully reflect the variety of care management services provided by informal caregivers and as a result may undervalue care. Applying a single wage rate to overall hours of informal care is at best a very crude approximation of the economic cost of care.

The ability of stated-preference measures to generate reliable valuations of informal care time is unclear. In particular, the three published DCE/CA studies yielded widely varying monetary estimates of the value of an hour of care. It appears that the specific way that scenarios are framed can be highly influential. Notably, if the monetary attribute is not anchored to prevailing hourly wages for paid care, as was done in one study [74], resulting estimates appear to be much lower than replacement cost estimates $[38,75]$. On the other hand, these methods allow for differential monetary estimates varying by number of daily hours of care and the perceived unpleasantness of care tasks.

\section{Conclusions}

This review summarizes and critiques the many different approaches that have been considered for measuring and valuing informal care for CEA. Virtually none of the studies reviewed considered the consequences of a given approach for a CEA that also sought to incorporate caregiver health effects. Some approaches, especially CV and DCEs, create the potential for double counting if care is not taken to estimate pure time values. Another issue is endogeneity between informal care time and health. The Second US Panel argues for using the human capital approach to value productivity loss for both patients and caregivers. Inclusion of lost leisure time in addition to work time ignores the potential endogeneity of health with regard to time spent in informal care to the extent it displaces personal care time.

Important strides have been made in the valuation of informal care, but the diversity of methods, assumptions, and estimates results in a great deal of uncertainty in the magnitude of the economic burden of informal care. It might be possible someday to produce off-the-shelf estimates of informal care costs based on caregiver characteristics and patient conditions, but such estimates will necessarily differ depending on the methods used to measure and value informal care time. Additional work in this area should consider the implications of different approaches for the inclusion of both health and productivity effects of informal care in COI analyses and CEA. Whatever methods of measurement and valuation of informal care are used, the strengths and limitations should be addressed, along with a justification for the chosen methods.

Acknowledgements The authors thank Allen Goodman and Ruth Perou for helpful comments based on content knowledge (personal communications).

Author contributions SDG conceptualized the study and wrote the initial draft of the first sections. SDG, JP, RS, and JMT each participated in the drafting of the other sections. JP, RS, and JMT provided feedback and SDG, JP, RS, and JMT edited multiple versions. SDG, JP, and JMT finalized the manuscript.

Funding No sources of funding were used to conduct this study or prepare this manuscript. The findings and conclusions in this report are those of the authors and do not necessarily represent the official position of the Centers for Disease Control and Prevention.

Conflict of interest Scott D. Grosse, Jamison Pike, Rieza Soelaeman, and J. Mick Tilford have no conflicts of interest that are directly relevant to the content of this article.

Open Access This article is distributed under the terms of the Creative Commons Attribution-NonCommercial 4.0 International License (http://creativecommons.org/licenses/by-nc/4.0/), which permits any noncommercial use, distribution, and reproduction in any medium, provided you give appropriate credit to the original author(s) and the source, provide a link to the Creative Commons license, and indicate if changes were made.

\section{References}

1. Basu A, Meltzer D. Implications of spillover effects within the family for medical cost-effectiveness analysis. J Health Econ. 2005;24(4):751-73.

2. Lavelle TA, Wittenberg E, Lamarand K, Prosser LA. Variation in the spillover effects of illness on parents, spouses, and children of the chronically ill. Appl Health Econ Health Policy. 2014;12(2):117-24.

3. Prosser LA, Lamarand K, Gebremariam A, Wittenberg E. Measuring family HRQoL spillover effects using direct health utility assessment. Med Decis Mak. 2015;35(1):81-93. 
4. Bobinac A, van Exel NJ, Rutten FF, Brouwer WB. Health effects in significant others: separating family and care-giving effects. Med Decis Mak. 2011;31(2):292-8.

5. Lamsal R, Zwicker JD. Economic evaluation of interventions for children with neurodevelopmental disorders: opportunities and challenges. Appl Health Econ Health Policy. 2017;15(6):763-72.

6. Gold MR, Siegel JE, Russell LB, Weinstein MC. Cost-effectiveness in health and medicine. New York: Oxford University Press; 1996.

7. Busschbach JJ, Brouwer WB, van der Donk A, Passchier J, Rutten FF. An outline for a cost-effectiveness analysis of a drug for patients with Alzheimer's disease. Pharmacoeconomics. 1998;13(1 Pt 1):21-34.

8. Krol M, Papenburg J, van Exel J. Does including informal care in economic evaluations matter? A systematic review of inclusion and impact of informal care in cost-effectiveness studies. Pharmacoeconomics. 2015;33(2):123-35.

9. Neumann P, Hermann R, Kuntz K, Araki S, Duff S, Leon J, et al. Cost-effectiveness of donepezil in the treatment of mild or moderate Alzheimer's disease. Neurology. 1999;52(6):1138-45.

10. Sanders GD, Neumann PJ, Basu A, Brock DW, Feeny D, Krahn $\mathrm{M}$, et al. Recommendations for conduct, methodological practices, and reporting of cost-effectiveness analyses: Second Panel on Cost-Effectiveness in Health and Medicine. JAMA. 2016;316(10):1093-103.

11. Brouwer WB, van Exel NJ, Koopmanschap MA, Rutten FF. The valuation of informal care in economic appraisal. A consideration of individual choice and societal costs of time. Int J Technol Assess Health Care. 1999;15(1):147-60 (Winter).

12. Brouwer W, van Exel J, Tilford JM. Incorporating caregiver and family effects in economic evaluations of child health. In: Ungar W, editor. Economic evaluation in child health. Oxford: Oxford University Press; 2009. p. 55-76.

13. Tilford JM, Payakachat N. Progress in measuring family spillover effects for economic evaluations. Expert Rev Pharmacoecon Outcomes Res. 2015;15(2):195-8.

14. Weatherly H, Faria R, Van Den Berg B. Valuing informal care for economic evaluation. Encyclopedia of Health Economics. New York: Elsevier; 2014. p. 459-67.

15. Hoefman RJ, van Exel J, Brouwer W. How to include informal care in economic evaluations. Pharmacoeconomics. 2013;31(12):1105-19.

16. Wittenberg E, Prosser LA. Disutility of illness for caregivers and families: a systematic review of the literature. Pharmacoeconomics. 2013;31(6):489-500.

17. Bobinac A, van Exel NJ, Rutten FF, Brouwer WB. Caring for and caring about: disentangling the caregiver effect and the family effect. J Health Econ. 2010;29(4):549-56.

18. Hoefman RJ, van Exel J, Brouwer WBF. The monetary value of informal care: obtaining pure time valuations using a discrete choice experiment. Pharmacoeconomics. 2018. https://doi. org/10.1007/s40273-018-0724-4.

19. Bonsang E. Does informal care from children to their elderly parents substitute for formal care in Europe? J Health Econ. 2009;28(1):143-54.

20. Van Houtven CH, Coe NB, Skira MM. The effect of informal care on work and wages. J Health Econ. 2013;32(1):240-52.

21. Schmitz H, Westphal M. Informal care and long-term labor market outcomes. J Health Econ. 2017;56:1-18.

22. Van den Berg B, Spauwen P. Measurement of informal care: an empirical study into the valid measurement of time spent on informal caregiving. Health Econ. 2006;15(5):447-60.

23. Goodrich K, Kaambwa B, Al-Janabi H. The inclusion of informal care in applied economic evaluation: a review. Value Health. 2012;15(6):975-81.
24. Keating NC, Fast JE, Lero DS, Lucas SJ, Eales J. A taxonomy of the economic costs of family care to adults. J Econ Ageing. 2014;3:11-20.

25. Van den Berg B, Brouwer WB, Koopmanschap MA. Economic valuation of informal care. Eur J Health Econ. 2004;5(1):36-45.

26. Gronau R. Home production - a survey. In: Ashenfelter O, Layer $\mathrm{R}$, editors. Handbook of labor economics. Amsterdam: Elsevier; 1986. p. 273-304.

27. Flyckt L, Lothman A, Jorgensen L, Rylander A, Koernig T. Burden of informal care giving to patients with psychoses: a descriptive and methodological study. Int J Soc Psychiatry. 2013;59(2):137-46.

28. Romley JA, Shah AK, Chung PJ, Elliott MN, Vestal KD, Schuster MA. Family-provided health care for children with special health care needs. Pediatrics. 2017;139(1):e20161287. https:// doi.org/10.1542/peds.2016-1287

29. Hoefman R, van Exel N, Brouwer W. iMTA valuation of informal care questionnaire (iVICQ). Version; 2015.

30. Van den Berg B, Brouwer W, van Exel J, Koopmanschap M, van den Bos GA, Rutten F. Economic valuation of informal care: lessons from the application of the opportunity costs and proxy good methods. Soc Sci Med. 2006;62(4):835-45.

31. Riewpaiboon A, Riewpaiboon W, Ponsoongnern K, Van den Berg B. Economic valuation of informal care in Asia: a case study of care for disabled stroke survivors in Thailand. Soc Sci Med. 2009;69(4):648-53.

32. Hickenbottom SL, Fendrick AM, Kutcher JS, Kabeto MU, Katz SJ, Langa KM. A national study of the quantity and cost of informal caregiving for the elderly with stroke. Neurology. 2002;58(12):1754-9.

33. Joo H, Dunet DO, Fang J, Wang G. Cost of informal caregiving associated with stroke among the elderly in the United States. Neurology. 2014;83(20):1831-7.

34. Joo H, Zhang P, Wang G. Cost of informal care for patients with cardiovascular disease or diabetes: current evidence and research challenges. Qual Life Res. 2017;26(6):1379-86.

35. Joo H, Wang G, Yee SL, Zhang P, Sleet D. Economic burden of informal caregiving associated with history of stroke and falls among older adults in the US. Am J Prev Med. 2017;53:S197-204.

36. Ostbye T, Crosse E. Net economic costs of dementia in Canada. CMAJ. 1994;151(10):1457-64.

37. Rice DP, Fox PJ, Max W, Webber PA, Lindeman DA, Hauck WW, et al. The economic burden of Alzheimer's disease care. Health Aff (Millwood). 1993;12(2):164-76 (Summer).

38. van den Berg B, Al M, Brouwer W, van Exel J, Koopmanschap M. Economic valuation of informal care: the conjoint measurement method applied to informal caregiving. Soc Sci Med. 2005;61(6): 1342-55.

39. Johnston RJ, Boyle KJ, Adamowicz W, Bennett J, Brouwer R, Cameron TA, et al. Contemporary guidance for stated preference studies. J Assoc Environ Resour Econ. 2017;4(2):319-405.

40. Weatherly H, Faria R, van den Berg B. quantifying informal care for economic evaluation in mental health. Mental health economics. Berlin: Springer; 2017. p. 267-80.

41. Posnett J, Jan S. Indirect cost in economic evaluation: the opportunity cost of unpaid inputs. Health Econ. 1996;5(1):13-23.

42. Diederich F, Konig HH, Mietzner C, Brettschneider C. Costs of informal nursing care for patients with neurologic disorders: a systematic review. Neurology. 2017;90:28-34.

43. Guerriere DN, Tranmer JE, Ungar WJ, Manoharan V, Coyte PC. Valuing care recipient and family caregiver time: a comparison of methods. Int J Technol Assess Health Care. 2008;24(1):52-60. 
44. Pena-Longobardo LM, Oliva-Moreno J. Economic valuation and determinants of informal care to people with Alzheimer's disease. Eur J Health Econ. 2015;16(5):507-15.

45. Grosse SD, Krueger KV. The income-based human capital valuation methods in public health economics used by forensic economics. J Forensic Econ. 2011;22(1):43-57.

46. Grosse SD, Krueger KV, Mvundura M. Economic productivity by age and sex: 2007 estimates for the United States. Med Care. 2009;47:S94-103.

47. Koopmanschap MA, van Exel NJA, van den Berg B, Brouwer WB. An overview of methods and applications to value informal care in economic evaluations of healthcare. Pharmacoeconomics. 2008;26(4):269-80.

48. Ernst RL, Hay JW. The US economic and social costs of Alzheimer's disease revisited. Am J Public Health. 1994;84(8):1261-4.

49. van den Berg B, Brouwer W, van Exel J, Koopmanschap M. Economic valuation of informal care: the contingent valuation method applied to informal caregiving. Health Econ. 2005; 14(2):169-83.

50. Arno PS, Levine C, Memmott MM. The economic value of informal caregiving. Health Aff (Millwood). 1999;18(2):182-8.

51. Gross J. Home health aides: what they make, what they cost. New York Times. 2008.

52. Hollander MJ, Liu G, Chappell NL. Who cares and how much? The imputed economic contribution to the Canadian healthcare system of middle-aged and older unpaid caregivers providing care to the elderly. Healthcare Q. 2009;12(2):42-9.

53. Rosenthal CJ, Martin-Matthews A, Keefe JM. Care management and care provision for older relatives amongst employed informal care-givers. Ageing Soc. 2007;27(5):755-78.

54. Fast JE, Williamson DL, Keating NC. The hidden costs of informal elder care. J Fam Econ Issues. 1999;20(3):301-26.

55. Luce BR, Manning WG, Siegel JE, Lipscomb J. Estimating costs in cost-effectiveness analysis. In: Gold MR, Siegel JE, Russell LB, Weinstein MC, editors. Cost-effectiveness in health and medicine. New York: Oxford University Press; 1996.

56. Clark RE, Teague GB, Ricketts SK, Bush PW, Xie H, McGuire TG, et al. Cost-effectiveness of assertive community treatment versus standard case management for persons with co-occurring severe mental illness and substance use disorders. Health Serv Res. 1998;33(5 Pt 1):1285-308.

57. Getsios D, Blume S, Ishak KJ, Maclaine GD. Cost effectiveness of donepezil in the treatment of mild to moderate Alzheimer's disease: a UK evaluation using discrete-event simulation. Pharmacoeconomics. 2010;28(5):411-27.

58. Egger N, Konnopka A, Beutel ME, Herpertz S, Hiller W, Hoyer J, et al. Short-term cost-effectiveness of psychodynamic therapy and cognitive-behavioral therapy in social anxiety disorder: Results from the SOPHO-NET trial. J Affect Disord. 2015; 15(180):21-8.

59. Baxter JR, Robinson LA, Hammitt JK. Valuing Time in U.S. Department of health and human services regulatory impact analyses: conceptual framework and best practices. 2017. Final report, June 2017. Available online at https://aspe.hhs.gov/syste m/files/pdf/257746/VOT.pdf

60. Kelly AE, Haddix AC, Scanlon KS, Helmick CG, Mulinare J. Cost-effectiveness of strategies to prevent neural tube defects. In: Gold MR, Siegel JE, Russell LB, Weinstein MC, editors. Cost-effectiveness in health and medicine. New York: Oxford University Press; 1996. p. 312-49.

61. Hodgson TA, Meiners MR. Cost-of-illness methodology: a guide to current practices and procedures. Milbank Mem Fund Q Health Soc. 1982;60(3):429-62 (Summer).

62. Krol M, Brouwer W. How to estimate productivity costs in economic evaluations. Pharmacoeconomics. 2014;32(4):335-44.
63. Tranmer JE, Guerriere DN, Ungar WJ, Coyte PC. Valuing patient and caregiver time: a review of the literature. Pharmacoeconomics. 2005;23(5):449-59.

64. Andersson A, Levin L-Ä, Emtinger BG. The economic burden of informal care. Int J Technol Assess Health Care. 2002;18(1):4654 (Winter).

65. Lilly MB, Laporte A, Coyte PC. Labor market work and home care's unpaid caregivers: a systematic review of labor force participation rates, predictors of labor market withdrawal, and hours of work. Milbank Q. 2007;85(4):641-90.

66. Lilly MB, Laporte A, Coyte PC. Do they care too much to work? The influence of caregiving intensity on the labour force participation of unpaid caregivers in Canada. J Health Econ. 2010;29(6):895-903.

67. Nguyen HT, Connelly LB. The effect of unpaid caregiving intensity on labour force participation: results from a multinomial endogenous treatment model. Soc Sci Med. 2014;100:115-22.

68. Tilford JM, Grosse SD, Goodman AC, Li K. Labor market productivity costs for caregivers of children with spina bifida: a population-based analysis. Med Decis Mak. 2009;29(1):23-32.

69. Landfeldt E, Lindgren P, Bell CF, Schmitt C, Guglieri M, Straub $\mathrm{V}$, et al. The burden of Duchenne muscular dystrophy: an international, cross-sectional study. Neurology. 2014;83(6):529-36.

70. Cidav Z, Marcus SC, Mandell DS. Implications of childhood autism for parental employment and earnings. Pediatrics. 2012;129(4):617-23.

71. Johnson FR, Lancsar E, Marshall D, Kilambi V, Mühlbacher A, Regier DA, et al. Constructing experimental designs for discrete-choice experiments: report of the ISPOR conjoint analysis experimental design good research practices task force. Value Health. 2013;16(1):3-13.

72. Bridges JF, Hauber AB, Marshall D, Lloyd A, Prosser LA, Regier DA, et al. Conjoint analysis applications in health-a checklist: a report of the ISPOR Good Research Practices for Conjoint Analysis Task Force. Value Health. 2011;14(4):403-13.

73. Clark MD, Determann D, Petrou S, Moro D, de Bekker-Grob EW. Discrete choice experiments in health economics: a review of the literature. Pharmacoeconomics. 2014;32(9):883-902.

74. Van den Berg B, Al M, Van Exel J, Koopmanschap M, Brouwer W. Economic valuation of informal care: conjoint analysis applied in a heterogeneous population of informal caregivers. Value Health. 2008;11(7):1041-50.

75. Mentzakis E, Ryan M, McNamee P. Using discrete choice experiments to value informal care tasks: exploring preference heterogeneity. Health Econ. 2011;20(8):930-44.

76. de Meijer C, Brouwer W, Koopmanschap M, van den Berg B, van Exel $J$. The value of informal care-a further investigation of the feasibility of contingent valuation in informal caregivers. Health Econ. 2010;19(7):755-71.

77. Garrido-García S, Sánchez-Martínez F-I, Abellán-Perpiñán J-M, van Exel J. Monetary valuation of informal care based on carers' and noncarers' preferences. Value Health. 2015;18(6):832-40.

78. Lancsar E, Swait J. Reconceptualising the external validity of discrete choice experiments. Pharmacoeconomics. 2014;32(10):951-65.

79. List JA, Shogren JF. Calibration of willingness-to-accept. J Environ Econ Manag. 2002;43(2):219-33.

80. Murphy JJ, Allen PG, Stevens TH, Weatherhead D. A meta-analysis of hypothetical bias in stated preference valuation. Environ Resour Econ. 2005;30(3):313-25.

81. Mohammadi T, Bansback N, Marra F, Khakban A, Campbell JR, FitzGerald JM, et al. Testing the external validity of a discrete choice experiment method: an application to latent tuberculosis infection treatment. Value Health. 2017;20:969-75. 
82. Johnson FR, Mohamed AF, Özdemir S, Marshall DA, Phillips KA. How does cost matter in health-care discrete-choice experiments? Health Econ. 2011;20(3):323-30.

83. Grosse SD, Flores AL, Ouyang L, Robbins JM, Tilford JM. Impact of spina bifida on parental caregivers: findings from a survey of Arkansas families. J Child Fam Stud. 2009;18(5):574-81.

84. Tilford JM, Payakachat N, Kuhlthau KA, Pyne JM, Kovacs E, Bellando J, et al. Treatment for sleep problems in children with autism and caregiver spillover effects. J Autism Dev Disord. 2015;45(11):3613-23.

85. Anderson D, Dumont S, Jacobs P, Azzaria L. The personal costs of caring for a child with a disability: a review of the literature. Public Health Rep. 2007;122(1):3-16.

86. DeRigne L. The employment and financial effects on families raising children with special health care needs: an examination of the evidence. J Pediatr Health Care. 2012;26(4):283-90.

87. Grosse SD. Sociodemographic characteristics of families of children with Down syndrome and the economic impacts of child disability on families. Int Rev Res Mental Retard. 2010;39:257-94.

88. Schaller S, Mauskopf J, Kriza C, Wahlster P, Kolominsky-Rabas PL. The main cost drivers in dementia: a systematic review. Int J Geriatr Psychiatry. 2015;30(2):111-29.

89. Stabile M, Allin S. The economic costs of childhood disability. Future Child. 2012;22(1):65-96 (Spring).

90. Tilford JM, Robbins JM, Hobbs CA. Improving estimates of caregiver time cost and family impact associated with birth defects. Teratology. 2001;64(Suppl 1):S37-41.

91. Buescher AV, Cidav Z, Knapp M, Mandell DS. Costs of autism spectrum disorders in the United Kingdom and the United States. JAMA Pediatr. 2014;168(8):721-8.

92. Gordon M, Rosenman L, Cuskelly M. Constrained labour: maternal employment when children have disabilities. J Appl Res Intellect Disab. 2007;20(3):236-46.

93. Grosse SD, Berry RJ, Mick Tilford J, Kucik JE, Waitzman NJ. Retrospective assessment of cost savings from prevention: folic acid fortification and spina bifida in the U.S. Am J Prev Med. 2016;50(5 Suppl 1):S74-80.

94. Grosse SD, Ouyang L, Collins JS, Green D, Dean JH, Stevenson RE. Economic evaluation of a neural tube defect recurrenceprevention program. Am J Prev Med. 2008;35(6):572-7.

95. Jarbrink K, Fombonne E, Knapp M. Measuring the parental, service and cost impacts of children with autistic spectrum disorder: a pilot study. J Autism Dev Disord. 2003;33(4):395-402.

96. Kogan MD, Strickland BB, Blumberg SJ, Singh GK, Perrin JM, van Dyck PC. A national profile of the health care experiences and family impact of autism spectrum disorder among children in the United States, 2005-2006. Pediatrics. 2008;122(6):e1149-58.

97. Lavelle TA, Weinstein MC, Newhouse JP, Munir K, Kuhlthau KA, Prosser LA. Economic burden of childhood autism spectrum disorders. Pediatrics. 2014;133(3):e520-9.

98. Loprest P, Davidoff A. How children with special health care needs affect the employment decisions of low-income parents. Matern Child Health J. 2004;8(3):171-82.

99. Okumura MJ, Van Cleave J, Gnanasekaran S, Houtrow A. Understanding factors associated with work loss for families caring for CSHCN. Pediatrics. 2009;124(Supplement 4):S392-8.

100. Wehby GL, Ohsfeldt RL. The impact of having a young child with disabilities on maternal labor supply by race and marital status. J Health Hum Serv Adm. 2007;30(3):327-51 (Winter).

101. Witt WP, Gottlieb CA, Hampton J, Litzelman K. The impact of childhood activity limitations on parental health, mental health, and workdays lost in the United States. Acad Pediatr. 2009;9(4):263-9.

102. Brehaut JC, Kohen DE, Raina P, Walter SD, Russell DJ, Swinton $\mathrm{M}$, et al. The health of primary caregivers of children with cerebral palsy: how does it compare with that of other Canadian caregivers? Pediatrics. 2004;114(2):e182-91.

103. Montes G, Halterman JS. Association of childhood autism spectrum disorders and loss of family income. Pediatrics. 2008;121(4):e821-6.

104. Chiwaula LS, Chirwa GC, Caltado F, Kapito-Tembo A, Hosseinipour MC, van Lettow $\mathrm{M}$, et al. The value of informal care in the context of option $\mathrm{B}+$ in Malawi: a contingent valuation approach. BMC Health Serv Res. 2016;16(1):136.

105. Gervès-Pinquié $\mathrm{C}$, Bellanger MM, Ankri J. Willingness to pay for informal care in France: the value of funding support interventions for caregivers. Health Econ Rev. 2014;4(1):34.

106. Gustavsson A, Jönsson L, McShane R, Boada M, Wimo A, Zbrozek AS. Willingness-to-pay for reductions in care need: estimating the value of informal care in Alzheimer's disease. Int J Geriatr Psychiatry. 2010;25(6):622-32.

107. König M, Wettstein A. Caring for relatives with dementia: willingness-to-pay for a reduction in caregiver's burden. Expert Rev Pharmacoecon Outcomes Res. 2002;2(6):535-47.

108. Van den Berg B, Bleichrodt H, Eeckhoudt L. The economic value of informal care: a study of informal caregivers' and patients' willingness to pay and willingness to accept for informal care. Health Econ. 2005;14(4):363-76. 